\title{
Creating A New Automotive Exterior Design Approach Model: The Relationship Between Form And Body Color Qualities
}

Maiko Muto, Aoyama Gakuin University, Japan Shohei Takebuchi, Aoyama Gakuin University, Japan Kakuro Amasaka, Aoyama Gakuin University, Japan

\begin{abstract}
This study creates a New Automotive Exterior Design Approach Model. Form and body color qualities are objectified (quantified) in order to grasp unspoken subjective customer impressions (preferences). Related cause-and-effect relationships are then clarified. This is done with the help of statistics, which are used to identify the main elements that younger buyers are looking for in automotive body colors. Next, a survey is conducted using painted panels to find out what color elements generate subjective customer impressions. Line-of-sight analysis and 3D-CAD software are used to assign numerical values to form and color, while research-oriented CAD models and biometric devices are used to quantify the impact that form and color have on subjective customer impressions. The insights gained from this are then used to understand the relationship between survey data assessing subjective impressions and qualities of form and body color. The resulting knowledge is then applied to optimally match form and body color in a way that customers find attractive. The desired results are obtained.
\end{abstract}

Keywords: Automobile; New Exterior Design Approach Model; Form and Body Color

\section{INTRODUCTION}

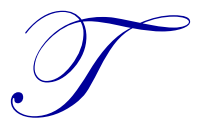

he idea of global quality competition in the auto industry has made developing body colors that best match the exterior design of vehicle models a critical factor in terms of product strategy, as color selection has the ability to affect consumer purchasing behavior. The rapid global advancement currently underway brings with it increasingly diverse and complex personal values and subjective impressions, which are difficult to fully grasp.

However, manufacturers that cannot accurately identify these consumer values and subjective impressions and incorporate the corresponding elements in their vehicle designs will find it difficult to remain competitive in the market. The authors have therefore concluded that traditional design processes, which are implicit and rely heavily on designer intuition and experience-based rules of thumb, must be reformed (Amasaka, 2005; Amasaka, 2007; Amasaka et al., 1999; Asami et al., 2010; Muto et al., 2011; Yamaji et al., 2009).

To address these issues, the authors have created a New Automotive Exterior Design Approach Model designed to optimally match form and body color (the key elements of automotive exterior design) in a way that customers find attractive. In order to identify unspoken subjective customer impressions (preferences), the model objectifies (quantifies) form and body color qualities and outlines related cause-and-effect relationships.

The following presents a detailed outline of the steps taken in this study:

1. Statistics are used to identify the main elements that younger buyers are looking for in automotive body colors.

2. A survey is conducted using painted panels to find out what color elements generate subjective customer impressions. 
3. $\quad 3 \mathrm{D}-\mathrm{CAD}$ software is used to assign numerical values to form and color.

4. Those results are used to generate research-oriented CAD models, which are used along with biometric devices to quantify the impact that form and color have on subjective customer impressions.

5. The relationship between survey data assessing subjective impressions and qualities of form and body color are identified; and finally.

6. The authors apply their newly developed Automotive Exterior Design Approach Model to optimally match form and body color in a way that customers find attractive, and the desired results are obtained.

\section{BACKGROUND}

Similar research was done by the authors (Asami et al., 2010). The authors constructed an "Automobile Exterior Design Approach Model" (AEDAM) which used biometric devices along with visualization technology and statistics to establish the relationship between vehicle form and color and customers' subjective responses.

First, they analyzed lines of sight using an eye camera to understand the perspectives from which customers observe overall automobile design. The subjective data collected during this process was then used to create a numerical model that measures form and color according to an objective scale. Finally, this information was used to construct and assess an evaluation model, and the given results are obtained. The effectiveness of this model was then verified.

However as a problem, it includes the point that does not take feel of a material peculiar to a car body color. This study goes further by taking into account the unique qualities of automotive body color, quantifying form and color, and identifying how these elements relate to customers.

\section{CREATING A NEW AUTOMOTIVE EXTERIOR DESIGN APPROACH MODEL}

In order to optimally match form and color in a way that customers find attractive, the authors have set up a New Automotive Exterior Design Approach Model (Figure 1).

The authors think it is important to visualize customer preference and make use of this information in product development, and thus created this model shown in Figure 1 which plays an important role in the development. Steps 1 to 4 show an outline of this model.

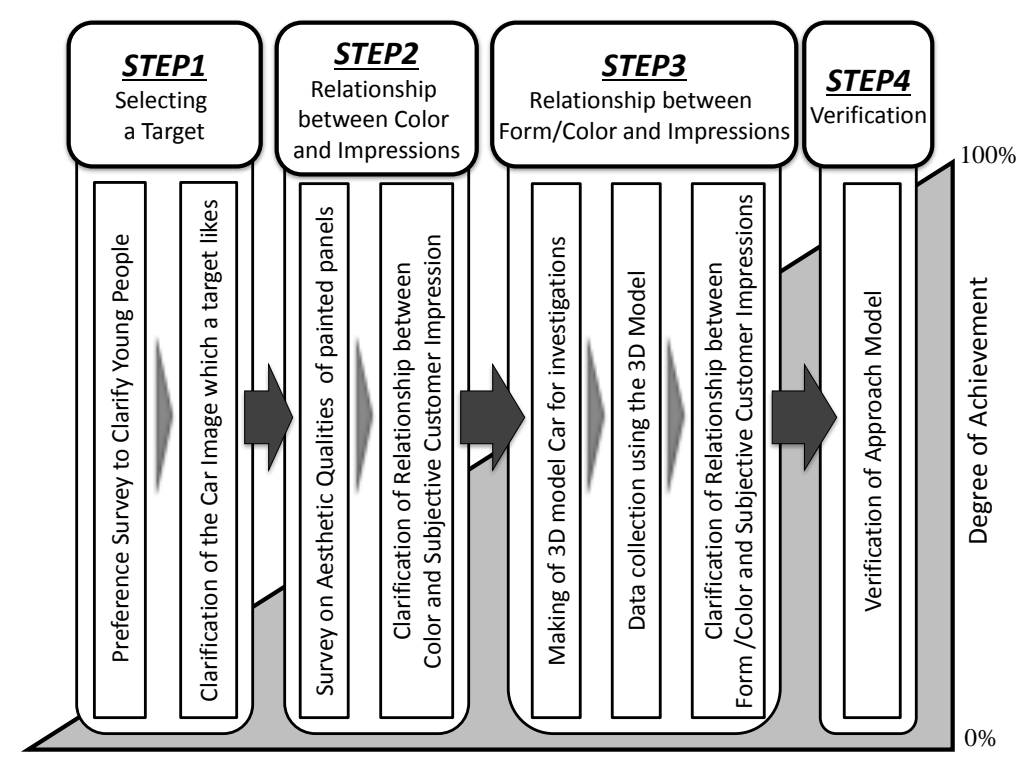

Figure 1: New Automotive Exterior Design Approach Model 


\section{SELECTING A TARGET (STEP 1)}

In selecting a target, the authors grouped customers by preference and then identified what the target group wanted from automotive design. A preference study was conducted using a fashion collage and the results were subjected to cluster and principle component analyses. The results revealed that younger customers could be divided into five groups according to preference - practically oriented, disinterested, self-expressive, appearance-oriented, and function-oriented.

The characteristics of the self-expressive group were strong preferences and a desire to express their personal status and image through their vehicle. This group was also the most interested in cars, so the authors decided to use the self-expressive group as the subject of this study. The analysis results also indicated three basic colors preferred by the target group - black, brown, and red. Four preference elements for this group were then identified as classy, luxurious, dignified, and sporty. In this way, the authors arrived at their target group, four preference elements, and three preferred base colors.

\section{IDENTIFYING THE RELATIONSHIP BETWEEN COLOR AND SUBJECTIVE CUSTOMER IMPRESSIONS (STEP 2)}

In order to grasp the relationship between the four subjective automobile qualities prized by members of the target group (classy, luxurious, dignified, and sporty), a survey was conducted using painted panels to identify the effect of color on subjective customer impressions.

The study used three basic color characteristics (hue, brightness, and saturation) plus three additional qualities unique to automotive coloration, for a total of six automotive color parameters - hue, brightness, saturation, luminosity, shading, and graininess. Luminosity indicates the degree of light reflectiveness, while shading indicates the difference in brightness between areas of light and shadow. Graininess refers to the size of the sparkling materials in the paint that reflect light when it hits the vehicle (Fujieda et al., 2007; Satake et al., 2004).

The authors then integrated these color parameters with the three automotive colors preferred by the target group (red, brown, and black) to come up with a total of 11 colored panels. Test subjects were asked to look at the panels and rate how well each one evoked the four subjective qualities (classy, luxurious, dignified, and sporty). This data was then subjected to a covariance structure analysis.

In the model diagram used for this covariance structure analysis, exterior color was designated as the latent variable satisfying the four subjective qualities (classy, luxurious, dignified, and sporty).

The authors then conducted a path analysis to figure out the cause-and-effect relationships between the six color parameters and exterior colors and then calculated standardized estimates. Looking at the standardized estimates in the model diagram, we can see the level of impact of each parameter as well as the directionality of that effect (Figure 2).

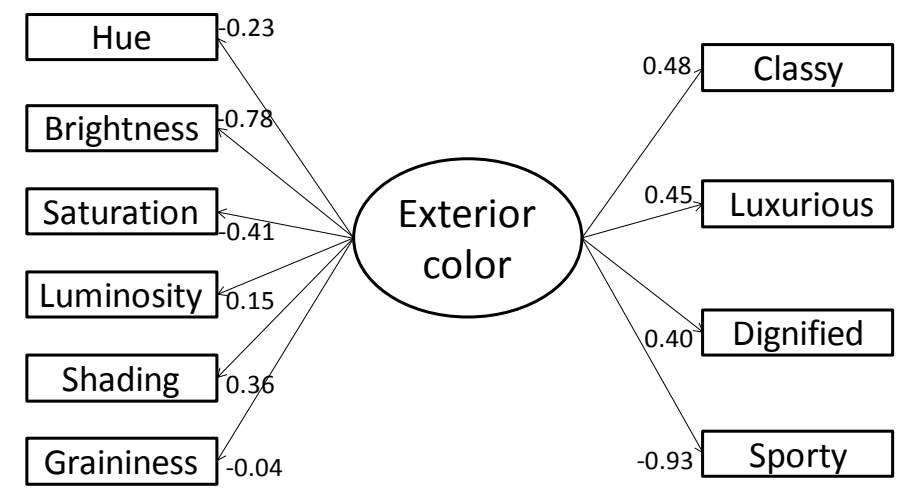

Figure 2: The Model Diagram of Covariance Structure Analysis and Standardized Estimates 
The results tell us that in order to produce exterior colors that match the preferences of the self-expressive group, we need to increase brightness and saturation while strengthening shading characteristics. The next section will deal specifically with the quality of shading.

\section{IDENTIFYING THE RELATIONSHIP BETWEEN FORM/COLOR AND SUBJECTIVE CUSTOMER IMPRESSIONS (STEP 3)}

In this section, a CAD model was used to conduct a subjective impression survey and clarify the relationship between automotive form/design and subjective customer preferences. In order to build the CAD model to be used in the survey, the authors focused particularly on designing the four priority areas and distinctive factors known to contribute significantly to automotive form.

As shown in Figure 3, these were identified in prior research (Asami et al., 2010; Takebuchi et al., 2012) as: 1) the edge of the hood, 2) the belt line, 3) the front pillar (A pillar), and 4) the rear pillar (C pillar).
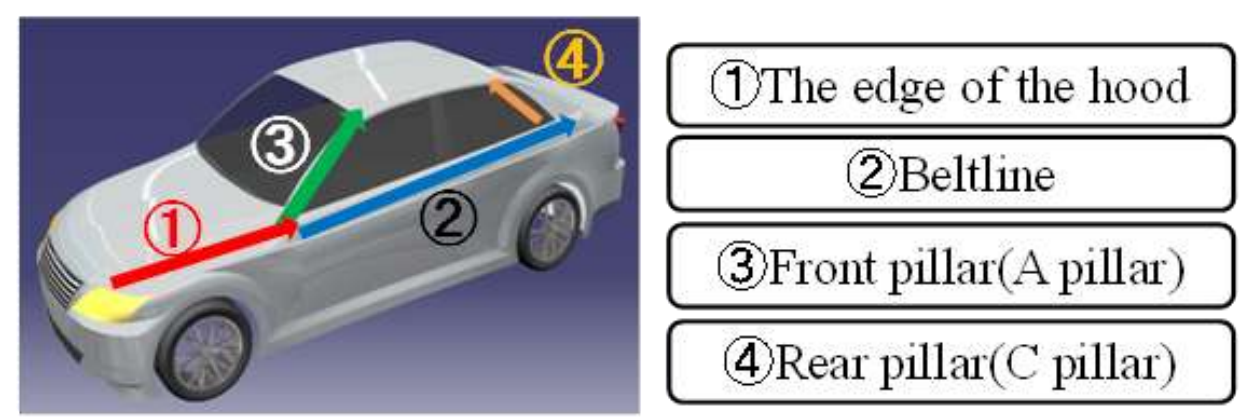

Figure 3: Four Priority Areas of the Automotive Model

With these four priority areas defined as key factors, the degree to which form was modified for each factor was used as one standard to define the model vehicles created for the survey. Here, the authors considered the overall balance of the vehicle design, setting up the following two core elements in order to maintain integrity of form: (1) depth of the edge of the hood and angle of the belt line (Form Element A) and (2) the front and rear pillars (Form Element B).

By keeping the modifications to these standards consistent in terms of direction, the authors were able to come up with four vehicle models for the subjective impression survey that maintained design balance. With these four models as a base, they then applied three color standards and two shading standards to create a total of 24 vehicle options (Figure 4).

\begin{tabular}{|c|c|c|c|c|c|c|}
\hline & \multicolumn{2}{|c|}{ Form factor $A$} & \multicolumn{2}{|c|}{ Form factor $B$} & & \\
\hline & Edge of & Beltline & A pillar & C pillar & & \\
\hline & the hood & & & & \multirow{2}{*}{ Exterior Color } & \multirow{2}{*}{$\begin{array}{l}\text { Quality } \\
\text { (Shading) }\end{array}$} \\
\hline Type A & $15^{\circ}$ & $0^{\circ}$ & $30^{\circ}$ & $20^{\circ}$ & & \\
\hline Type B & $45^{\circ}$ & $5^{\circ}$ & $30^{\circ}$ & $20^{\circ}$ & \multirow{2}{*}{$\begin{array}{c}3 \text { colors } \\
\text { (Red,Brown,Brack) }\end{array}$} & \multirow{2}{*}{ Big,Small } \\
\hline Type C & $15^{\circ}$ & $0^{\circ}$ & $60^{\circ}$ & $60^{\circ}$ & & \\
\hline Type D & $45^{\circ}$ & $5^{\circ}$ & $60^{\circ}$ & $60^{\circ}$ & & \\
\hline
\end{tabular}

Figure 4: The Parameters of the Automotive Model

Two types of data were then collected using the vehicle models created for the subjective impression survey - subjective evaluation data and biometric measurement data (using an eye-tracking camera). For the first type of data, the subjects were asked to look at the vehicle models prepared for the subjective impression survey and rate the degree to which they felt the subjective automobile qualities applied to each on a seven-point scale. For the second type of 
data, subjects looked at the same vehicle models while wearing an eye-tracking camera to measure line-of-sight information.

Next, the subjective evaluation data and vehicle model parameters were subject to a Quantitative Theory Type I analysis in order to pinpoint the degree to which aspects of the vehicle - like form and color qualities - impact subjective customer impressions. The Quantitative Theory Type I analysis was conducted using the 12 subjective qualities as external criteria and form and color - Form element A, Form element B, Color, Quality (Shading) - as items. The authors looked at partial regression coefficient values from the items to the external criteria to identify the level of impact for each variable as well as the direction of that impact.

Following is one example from the analysis. When looking at the external criterion "sporty", the authors found a determination coefficient of 0.628. For the individual items - Form Element A - it was found that raising the angle of the belt line and hood edge angle gave the vehicle a more "sporty" form. For Form Element B, it was found that if brown was used as the standard color, changing the color to black made the vehicle seem less sporty, while changing it to red made it seem more sporty. Finally, the authors found that eliminating shading effects caused the vehicle to lose its sportiness. These results made it possible to identify both the degree and direction of impact that form and color have on creating the desired vehicle image.

Next, the authors defined the interplay between aspects - like form and color - by clarifying the interactions between the different variables with an analysis of variance. This was done in order to identify the effects occurring between variables themselves. Here, we present the example of "sporty" used as the objective variable in the analysis of variance (Table 1). Factor A is Form Element A, factor B is Form Element B, factor C is color, and factor D is color quality.

Table 1: The Analysis Example of "Sporty" Used as the Objective Variable

\begin{tabular}{|r|l|l|r|r|r|r|r|r|}
\hline & & Factor & $\begin{array}{c}\text { Sum of } \\
\text { squares }\end{array}$ & $\begin{array}{c}\text { Degree of } \\
\text { freedom }\end{array}$ & Variance & $\begin{array}{c}\text { Variance } \\
\text { ratio }\end{array}$ & $\begin{array}{c}\text { Statistical } \\
\text { test }\end{array}$ & $\begin{array}{c}\text { P value } \\
\text { (upside) }\end{array}$ \\
\hline 1 & & $\mathrm{~A}$ & 310.537 & 1 & 310.537 & 276.402 & $* *$ & 0.000 \\
2 & & $\mathrm{~B}$ & 0.104 & 1 & 0.104 & 0.093 & & 0.761 \\
3 & & $\mathrm{AB}$ & 11.704 & 1 & 11.704 & 10.418 & $* *$ & 0.001 \\
4 & & $\mathrm{C}$ & 54.808 & 2 & 27.404 & 24.392 & $* *$ & 0.000 \\
5 & & $\mathrm{AC}$ & 11.325 & 2 & 5.663 & 5.040 & $* *$ & 0.007 \\
6 & & $\mathrm{BC}$ & 1.108 & 2 & 0.554 & 0.493 & & 0.611 \\
7 & & $\mathrm{D}$ & 168.337 & 1 & 168.337 & 149.833 & $* *$ & 0.000 \\
8 & & $\mathrm{AD}$ & 34.504 & 1 & 34.504 & 30.711 & $* *$ & 0.000 \\
9 & & $\mathrm{BD}$ & 0.504 & 1 & 0.504 & 0.449 & & 0.504 \\
10 & \multirow{2}{*}{$\mathrm{CD}$} & 3.675 & 2 & 1.838 & 1.636 & & 0.197 \\
11 & Error & $\mathrm{ABCDr}$ & 252.788 & 225 & 1.124 & & & \\
\hline 12 & \multicolumn{2}{|c|}{ Total } & 849.396 & 239 & & & & \\
\hline
\end{tabular}

The results showed interaction between form factors $\mathrm{A}$ and $\mathrm{B}, \mathrm{A}$ and $\mathrm{C}$, and $\mathrm{A}$ and $\mathrm{D}$, where a modification in each of these variables had a powerful impact on the other variable. When a cause-and-effect diagram is created with "sporty" as the objective variable, the results indicate that raising the angle of Form Element A, increasing the angles in Form Element B, making the color red, and intensifying the color quality creates the most "sporty" impression.

Using the eye-tracking camera, the authors also collected biometric measurement data on line-of-sight movements as well as the length of time subjects held their gaze at any one place. The line-of-sight heat map in Figure 6 compares two models with different shading characteristics. As you can see, the more shading led viewers to concentrate their gaze on the edge of the hood (Figure 5-1), while less shading caused them to focus more attention along the belt line (Figure5-2).

This suggests that the level of shading changes the way viewers look at the edge of the hood and beltline by impacting the customers' line of sight. 


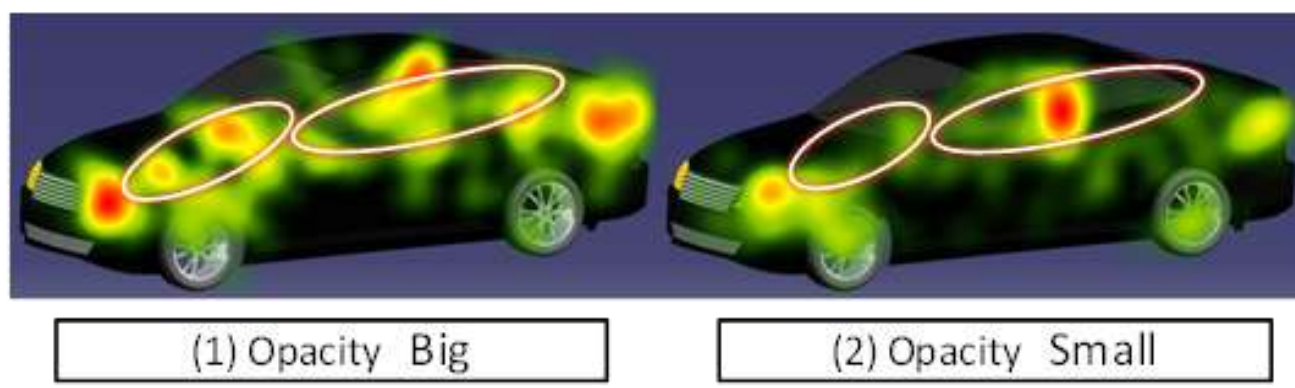

Figure 5: The Line-of-Sight Heat Map

At the same time, the authors were able to see the difference in how the eye tracks with and without shading by tracing the amount of time viewers spend gazing at particular points when shading is used as the color quality factor. The conclusion is that the difference in how the belt line and character line is seen is a function of the level of shading since shading affects customers' line of sight. Therefore, variables like form and color do not exist independently, but have a mutual effect on one another. This insight about mutual interaction was found to be true for each variable used in the analysis of variance study.

\section{VERIFICATION (STEP 4)}

In order to check the validity of the above analysis, the authors created a survey on the CAD models that had the "sporty" and "luxurious" automotive design qualities favored by the self-expressive group to see whether those models actually matched customers' images of them (Figure 6). The sporty model received an average verification score of 6.6 on the verification questionnaire, while the luxurious model received an average verification score of 6. These results confirm the validity of the analysis results obtained in Section 3, since these average scores were higher than the scores that other models received on those particular subjective quality evaluations.

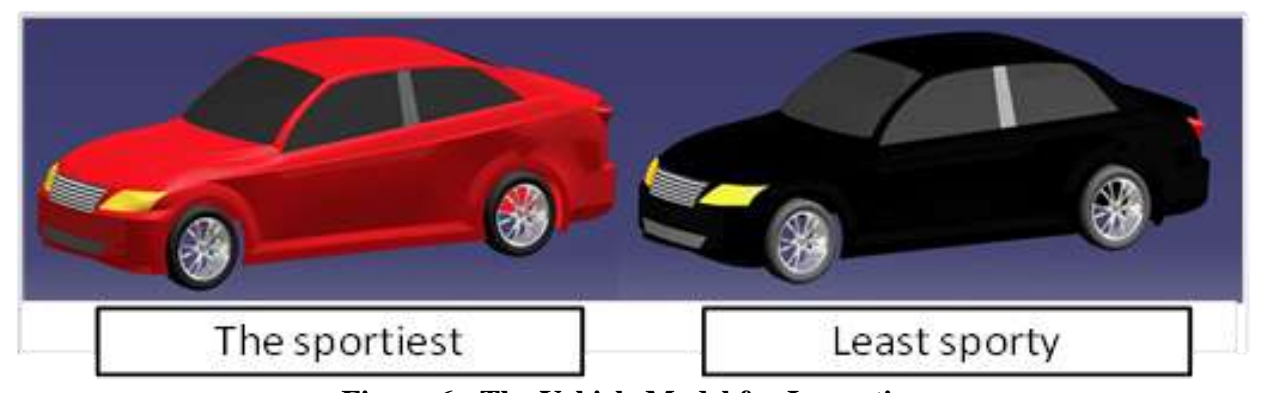

Figure 6: The Vehicle Model for Inspection

Next, the authors used a device that measures brain waves to quantitatively evaluate customer preferences and provide another indicator evaluating subjective impressions. The equipment allowed the researchers to separate brainwave frequency into four bands - delta waves $(\sim 4 \mathrm{~Hz})$, theta waves $(4 \mathrm{~Hz} \sim 8 \mathrm{~Hz})$, alpha waves $(8 \mathrm{~Hz} \sim 13 \mathrm{~Hz})$, and beta waves $(13 \mathrm{~Hz})$. It is known that the brain emits more alpha waves when experiencing pleasure and more beta waves when experiencing displeasure. As an indicator for evaluating customer preference, the authors gave the subjects images to look at and then recorded their brainwaves, focusing on value calculated for alpha waves over the calculation value for beta waves, or $\alpha / \beta$ (Kawano et al., 2004; Takebuchi et al., 2012).

The authors showed the test subjects two CAD images of different vehicle models and measured their brainwaves as they looked at them. By extracting the alpha and beta waves measured as the subjects looked at the CAD models, and while calculating the ratio of alpha to beta for each one, the authors found that the size of the alpha-beta ratio was consistent with the degree to which they liked a given vehicle model. The ratio of alpha to beta waves used in this study can therefore be considered an effective way to grasp customer preference. With this, the validity of the analysis results obtained in Section 6 was considered verified. 


\section{CONCLUSIONS}

The authors have created a New Vehicle Exterior Design Approach Model. Form and body color qualities are objectified (quantified) in order to grasp unspoken subjective customer impressions (preferences). Related cause-and-effect relationships are then clarified and the desired results are obtained. Specifically, the authors selected younger customers as the target of the study, collected both subjective evaluation data and biometric measurement data on them, and then used statistical methods to analyze this data. The results indicated the relationship between subjective customer impressions and changes in vehicle form, color, and color qualities. The authors were thus able to find an ideal form and body color match that caused customers to find a vehicle attractive.

This approach model can be used in the trial production stage for vehicle models as a way to quantitatively capture the subjective characteristics that a particular model evokes. In addition, designers can use this model to determine which design parameters they can modify to bring a model closer to having the subjective characteristics they want to achieve.

Further research is needed in order to verify the effectiveness of this approach model in additional analysis conditions, such as those that use vehicle models - other than sedans - and other color qualities like depth and transparency.

\section{AUTHOR INFORMATION}

Maiko Muto is a graduate student of the College of Science and Engineering at Aoyama Gakuin University. E-mail: c5611174@aoyama.jp

Shohei Takebuchi received his Master of Engineering degree from the College of Science and Engineering at Aoyama Gakuin University. E-mail: c5610176@aoyama.jp

Dr. Kakuro Amasaka is a Professor in the College of Science and Engineering at Aoyama Gakuin University, Japan. He received his Ph.D. degree in Precision Mechanical and System Engineering, Statistics and Quality Control at Hiroshima University in 1997. Since joining Toyota Motor Corporation in 1968, he worked as a quality control consultant for many divisions and the General Manager of the TQM Promotion Division (1998-2000). His specialty is New JIT, Science TQM, Science SQC, Numerical Simulation (CAE) and Customer Science. Now he has been serving as the director of JSQC (2001-2003), the vice chairman of JSPM (2003-2007) and JOMSA (2008-2009), and the chairman of JOMSA (2010-2012). E-mail: Kakuro_amasaka@ise.aoyama.ac.jp (Corresponding author)

\section{REFERENCES}

1. Amasaka, K., (2005), "Constructing a Customer Science Application System "CS-CIANS"- Development of a global strategic vehicle "Lexus" utilizing New JIT -," WSEAS Transactions on Business and Economics, Issue3, Vol. 2, pp. 135-142.

2. Amasaka, K., (2007), "The validity of "TDS-DTM": A strategic methodology of merchandise development of New JIT - Key to the excellence design "LEXUS"," International Business \& Economics Research Journal, Vol. 6, No. 11, pp. 105-116.

3. Amasaka, K., Nagaya, A. and Shibata, W., (1999), "Studies on Design SQC with the application of Science SQC-Improving of business process method for automotive profile design," Japanese Journal of Sensory Evaluations, Vol. 3, No. 1, pp. 21-29.

4. Asami, H., Ando, T., Yamaji, M. and Amasaka, K., (2010), “A Study on Automobile Form Design Support Method "AFD-SM"," Journal of Business \& Economics Research, Vol. 8, No. 11, pp. 13-19.

5. Fujieda, T., Masuda, Y. and Nakahata, A., (2007), "Development of automotive color designing process," Journal of Society of Automotive Engineers of Japan, Vol. 61, No. 6, pp. 79-84.

6. Kawano, K., Konjiki, F. and Ago, Y., (2004), "Psychological effects and sexual differences in EEG values during collage making," Journal of International Society of Life Information Science, Vol. 22, No. 1, pp. 60-64. 
7. Muto, M., Miyake, R. and Amasaka, K., (2011), "Constructing an Automobile Body Color Development Approach Model,” Journal of Management Science, Vol. 2, No. 2, pp. 175-183.

8. Satake, I., Ando, K., Kuwano, K., Sato, T., Hattori, H. and Kajiwara, K., (2004), "Study on relationship between automotive exterior color and automotive shape category," Journal of the Color Science Association of Japan, Vol. 28, No. 2, pp. 102-110.

9. Takebuchi, S. and Amasaka, K., (2012), (A master's thesis) "The Automobile Exterior Color Design Approach Model,” Aoyama Gakuin Univercity. (Unpublished) (in Japanese).

10. Takebuchi, S., Asami, H. and Amasaka, K., (2012), "An Automobile Exterior Design Approach Model Linking Form and Color," China-USA Business Review, Vol. 10, No. 8, pp. 1113-1123.

11. Takebuchi, S., Nakamura, T., Asami, H. and Amasaka, K., (2012), "The Automobile Exterior Color Design Approach Model," Journal of Japan Industrial Management Association, Vol. 62, No. 6E, pp.303-310.

12. Yamaji, M. and Amasaka, K., (2009), "Intelligence Design Concept Method Utilizing Customer Science," The Open Industrial and Manufacturing Engineering Journal, Vol. 2, pp. 21-25. 